but in elderly patients we have found more problems are created than are solved.

\author{
Alberta Hospital Ponoka \\ Box 1000 \\ Ponoka, Alberta \\ TOC $2 \mathrm{HO}$ \\ Canada \\ The Grey Nuns Hospital \\ Edmonton, Alberta \\ Canada
}

Alan Byrne
Bryan Brunet

Paul McGanN

\section{Post-stroke rapid cycling bipolar affective disorder}

SIR: Blackwell (Journal, August 1991, 159, 279-280) reports the case of a young man who developed a rapid-cycling manic-depressive illness complicating a small brain stem haematoma. The following case report further illustrates the phenomenology of mood swings occurring in a patient who developed a very rapid-cycling affective disorder following a right hemisphere cerebrovascular accident.

Case report. The patient was a 44-year-old ambidextrous man who suffered an ischaemic infarct involving the right hemisphere (mainly temporo-insular and anterior parietal regions) that left him with a left hemiparesis and a left arm dystonia. He had a previous history of alcohol abuse but no positive family or personal history of affective disorder. Two months after his stroke, his wife noted that he began to experience abrupt changes in mood, even within a few hours, from jocularity to helplessness, and from talkativeness to elective mutism. Affective states were evaluated on repeated occasions using the Hamilton Rating Scale for Depression (HRSD) and the Mania Scale (MAS; Beck et al, 1986). During the manic phases he appeared distractible and elated, and joked inappropriately. At times he was irritable and occasionally exploded into a rage with only trivial precipitants. He also showed loud, pressured speech, flight of thoughts, and increased libido and activity. Through several manic episodes, his MAS score ranged from 13 (hypomania) to 18 points (definite mania). During depressive phases, he appeared apprehensive and forgetful, and showed a pessimistic attitude towards the future and total loss of libido. His HRSD scores were always above 16 points (major depression). It was noted that over a period of two weeks the patient had at least three mood swings per day. Bipolar cycles with intervening euthymic periods and very brief mixed affective states were also documented. The patient was started on treatment with carbamazepine $(600 \mathrm{mg} /$ day $)$, but he developed intolerable side effects, and the medication was discontinued. Lithium carbonate was then prescribed but it was withdrawn because of noncompliance. Rapid cycling spontaneously subsided one year after onset.
The phenomenological profiles of post-stroke depression and mania are both remarkably similar to those found in patients with functional affective disorders (Starkstein \& Robinson, 1989). Furthermore, seasonal patterns of bipolar illness (Hunt \& Silverstone, 1990) and unipolar mania (Berthier et al, 1990) have been reported after focal involvement of the limbic system. The occurrence of very rapid mood fluctuations between mania and depression alternating every two weeks in Blackwell's patient and on an hour-by-hour basis in the present case also parallels that of functional rapid-cycling bipolar affective disorder (Wolpert et al, 1990). Focal damage to the limbic system affecting midline structures (Blackwell, 1991) or the right hemisphere might be implicated in the pathogenesis of rapid-cycling bipolar affective disorder.

Bech, P., Kastrup, M. \& Rafaelsen, O. J. (1986) Minicompendium of rating scales for states of anxiety, depression, mania, and schizophrenia, with corresponding DSM-III syndromes. Acta Psychiatrica Scandinavica, 73 (suppl. 236), 29-31.

Berthier, M. L., Starkstein, S. E., Robinson, R. G., el al (1990) Limbic lesions in a patient with recurrent mania. Journal of Neuropsychiatry, 2, 235-236.

Hunt, N. \& Silverstone, T. (1990) Seasonal affective disorder following brain injury. British Journal of Psychiairy. 156, 884-886.

Starkstein, S. E. \& Robinson, R. G. (1989) Affective disorders and cerebral vascular disease. British Journal of Psychiatry, 154, $170-182$.

Wolprert, E. A., Goldberg, J. F. \& Harrow, M. (1990) Rapid cycling in unipolar and bipolar affective disorders. American Journal of Psychiatry, 147, 725-728.

Neurology Service,

MARCElo L. Berthier

Virgen de la Victoria University Hospital

Colonia Sta Inés $\mathbf{s} / \mathbf{n}$

Apartado 3091 (29001)

Málaga

Spain

Fluvoxamine withdrawal syndrome

SIR: Fluvoxamine is a selective 5-hydroxytryptamine (5-HT) uptake inhibitor that has been shown to be effective in the treatment of obsessive-compulsive disorder (OCD) (Goodman et al, 1990). I report here a patient who developed a distinct psychiatric syndrome whenever she stopped her fluvoxamine medication.

Case report. The patient was a 30-year-old woman in 1987 when her medication with fluvoxamine was started. She had a long history of OCD; the illness started at age 12 with compulsive hand-washing and bathing. Over the years her symptoms fluctuated; although there were a couple of years of good functioning, she was usually severely incapacitated 
by her symptoms (continuous preoccupation with dirt and contamination resulting in hours being spent in the bath and inability to leave her home). She spent long periods as a hospital in-patient. In April 1987, the patient was prescribed fluvoxamine $50 \mathrm{mg}$ b.d. There was a good therapeutic response, and the patient was discharged from hospital. In April 1988, after a year's treatment with fluvoxamine, the patient became pregnant, and her general practitioner advised her to stop the fluvoxamine. The patient, however, claimed that she was unable to stop her fluvoxamine; whenever she had tried to do so, she was overwhelmed by strong feelings of aggression (she felt that she "could murder someone"). As Duphar Laboratories, the manufacturers of fluvoxamine, were unaware of any adverse reports on the drug in pregnancy, and the patient's mental state was likely to deteriorate after discontinuation of medication, the patient was allowed to continue on her fluvoxamine throughout her pregnancy. The pregnancy was uneventful, and the patient gave birth to a healthy daughter. Later, when the dosage of fluvoxamine was increased to $150 \mathrm{mg}$ daily, the patient reported a new form of withdrawal syndrome: on the first day after stopping the medication she felt elated and had general features of hypomania (overactivity, racing of thoughts, lack of fatigue). On the second day, however, the aggressive feelings and thoughts appeared. While the patient found the hypomanic phase pleasant, she described the aggressive phase as unbearably distressing.

The bi-phasic withdrawal syndrome probably reflects the activation of two different mechanisms as the concentration of fluvoxamine declines in the brain: the drop in concentration from a higher level would trigger the hypomanic syndrome, whereas the fall in concentration from a lower level would result in the aggressive feelings. Indeed, when the patient was on the lower dosage $(100 \mathrm{mg} /$ day) of fluvoxamine, only the aggressive phase was reported.

The most plausible explanation for the withdrawal syndrome is that it reflects a relative deficiency of 5-HT at central 5-HT receptors. In the presence of fluvoxamine the uptake of released 5-HT is continuously blocked, resulting in the exposure of the receptors to a high concentration of 5-HT. This in turn could lead to "down-regulation" (desensitisation) of the receptors. When fluvoxamine is withdrawn, the concentration of 5-HT falls at the receptors to a level that is not sufficient to provide an adequate agonist stimulus for the down-regulated receptors. Indeed, a deficiency in 5-HT has been implicated in the pathogenesis of aggressive and impulsive behaviours (Coccaro, 1989). It is more difficult, however, to link the hypomanic syndrome to a deficiency in 5-HT since mania is thought to be associated with excessive concentrations of 5-HT at central 5-HT-ergic synapses (van Praag, 1978). A similar mechanism has been implicated in the pathogenesis of the neuroleptic malignant syndrome provoked by the discontinuation of levodopa therapy in Parkinsonian patients: stopping the medication leads to an acute relative deficiency of dopamine at central dopaminergic synapses (see Addonizio \& Susman, 1991).

I am not aware of other reports of a fluvoxamine withdrawal syndrome, and would be interested to hear from colleagues whether their patients reported similar experiences when withdrawn from fluvoxamine or other selective 5-HT uptake inhibitors (e.g. fluoxetine, paroxetine, sertraline).

Addonizio, G. \& Susman, V. L. (1991) Neuroleptic Malignant Syndrome: A Clinical Approach. St Louis: Mosby Year Book. CocCaro, E. F. (1989) Central serotonin and impulsive aggression. British Journal of Psychiatry. 155 (suppl. 8), 52-62.

Goodman, W. K., Price, L. H., Delgado, P. L., et al (1990) Specificity of serotonin reuptake inhibitors in the treatment of obsessive-compulsive disorder. Comparison of fluvoxamine and desipramine. Archives of General Psychiatry, 47, 577-585.

VAN PRAAG, H. M. (1978) Amine hypotheses of affective disorder. In Handbook of Psychopharmacology. Vol 13 (eds L. L. Iversen, S. D. Iversen \& S. H. Snyder), pp. 187-297. New York: Plenum Press.

Department of Psychiatry University of Nottingham Queen's Medical College Nottingham NG7 $2 \mathrm{UH}$ 